\title{
Fog Harvesting and IoT based Environment Monitoring System at the Ilalo volcano in Ecuador
}

\author{
David Carrera-Villacrés ${ }^{\#, *}$, Jose Luis Carrera Villacrés ${ }^{+}$, Torsten Braun ${ }^{+}$, Zhongliang Zhao ${ }^{+}$, \\ Javier Gómez ${ }^{\# 5^{*}}$, Joffre Quinteros-Carabali ${ }^{\# 6^{*}}$ \\ \# Universidad de las Fuerzas Armadas ESPE. Departmento de Ciencias de la Tierra y la Construcción. Av. Gral. Ruminahui S/N, Sangolquí, \\ 170501. Ecuador
}

*Universidad Central del Ecuador. Facultad de Ingeniería en Geología, Minas, Petróleos y Ambiental (FIGEMPA). Av. Universitaria, Quito,170521, Ecuador

E-mail:dvcarrera@espe.edu.ec

${ }^{+}$Universitat Bern, Bern, 3011, Switzerland

E-mail: torsten.braun@inf.unibe.ch

\begin{abstract}
Environmental monitoring is critical to developing appropriate policies for environmental sustainability. The quality of drinking and agricultural water is affected by bad environmental management strategies. In addition, natural water sources have been reduced due to climate changes and the lack of police and compliance with regulations for water resources management. In the Andes region of Ecuador, these problems have increased in recent decades. The lack of water affects not only human well-being, but also causes soil degradation. Therefore, finding alternative water sources has become the underlying requirement to provide human well-being and mitigate soil degradation in these regions. This article presents a fog collection system based on water condensation towers and Internet of Things (IoT) technology with real-time monitoring. Our system allows the monitoring of environmental parameters while providing alternative sources of water from the environmental fog. Therefore, by collecting information related to the process of fog collection and climatic measurements of the environment, we seek to determine the state and trends of environmental conditions with respect to the performance of fog collection. In addition, our system allows the storage of historical ecological data, which can be used to develop environmental management policies. We have deployed our system on the slopes of the Ilalo volcano, Pichincha province, being part of the Ecuadorian Andes, where the soil deterioration has increased in recent years and has the largest soil degradation rate in Ecuador.
\end{abstract}

Keywords - fog collector system; open-source platforms; degradation water and soil; Internet of Things (IoT); environmental monitoring.

\section{INTRODUCTION}

\section{A. Water and soil Degradation Cause of Ecuador}

The drinking and agriculture water quality is in bad condition in Ecuador. Moreover, natural water sources have been reduced due to climate changes.[1] These problems are compounded by poor management of resources and planetary climate variations. Lack of water affects not only human wellness but it also leads to soil degradation. Thus, finding alternative water sources is an underlying requirement to provide human wellness and mitigate soil degradation. Alternative water sources are fog collectors systems [2]. Fog collector systems are especially suitable in areas where the horizontal precipitation is abundant. In Ecuador, mountainous zones with more than 2800 meters above sea level (masl) have high level of horizontal precipitation. Thus, fog collector systems can be exploited as suitable alternative water source in these regions of Ecuador in South America [3].

Internet of Things (IoT) technology has increased attention due to the growing number of applications that rely on the ability to transfer data over a network without requiring human-to-human or human-to-computer interaction. Thus, IoT applications are widely used to provide environmental monitoring services.[4]

Ecuador is a country located on the equator line and crossed by the Andes Mountains. The Andes forms three natural regions within a relatively small territory. The three natural areas of Ecuador are Coast, Highlands, and Amazon [5]. The Highlands region covers the area belonging to the mountains range, with elevations that reach up to 6268 masl. 
Summits of the highlands region mostly correspond to volcanoes. Ecuador has various edaphological formations [6]. These volcanoes have shaped the geography of the region over time.

Some problems in Ecuador such as having one of the highest rates of deforestation in South America, population increase, conversion of large areas of mountain forests into pastures and crops, coupled with the rugged topography of the region, have caused the progress of erosive processes (in the inter Andean basin). Erosion leads to degradation of natural resources, especially water and soil, which is a vital and largely non-renewable resource [7], [8].

In addition, unsuitable agricultural practices, type of climate, changes in land use, and growth of the agricultural frontier have an impact on the sustainability of cultivable areas. However, these problems have affected also high mountain areas where water is formed in Ecuador. Moreover, native forests and moor soils are threatened in this region of Ecuador.

In this work, we present a fog harvesting system, which includes IoT based technology to provide an alternative water source while monitoring environmental parameters. Therefore, by collecting information related to the fog harvesting process and weather measurements from the surrounding environment, we aimed to establish a relationship between environmental parameters information and the water harvesting process. Our system implements water condensation towers along with sensor nodes. The sensor nodes enable monitoring of environmental temperature, humidity, air pressure, wind speed (anemometer), light intensity, visibility (i.e., microscopic water particles constituting fog), tank liquid level (i.e., amount of collected water). Moreover, the sensor nodes are solar powered and solar power consumption is also reported by the node. Collected information is sent via LoRa WAN to a central application server located at the University of Bern in Switzerland. Our system enables the storage of environmental historical data, which can be used for developing suitable environmental management policies.

\section{B. Fog Collectors Systems Installed around the World}

Fog water collection varies as a result of the peculiarities of advection fog at the site (drop size distribution, liquid water cloud content, wind regime) and meter collection efficiency [9]. Currently, three-dimensional meshes have been developed to optimize the collection [10]. An ideal fog harvesting structure is such that it recovers most of the liquid phase and evacuates quickly, while enabling the gas phase to pass freely [11]. Fog interception is a natural phenomenon that enables trees in fog-prone areas to collect water from the atmosphere and safeguard their existence even in waterscarce situations. Intercepted fog water has a significant contribution to the hydrological cycle [12]. Fog collectors' systems have been studied since immemorial time because of their positive and negative consequences. The history of fog water is not recent. It was born approximately in the 16th century in the archipelago of the Canary Islands, Spain. Historians say that a tree called Garoe was the means by which water was collected, (see Fig. 1). In 1990 in the Arabian Peninsula, this technique was used with two olive trees that delivered approximately 1,000 liters of water every day.

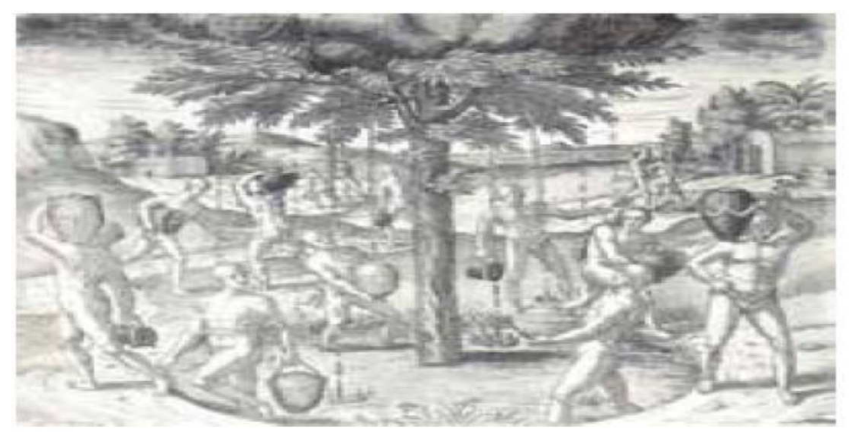

Fig. 1 Tree Garoe painted in century XVIII.

In Antofagasta, Chile, in the late 1950s, Professor Carlos Espinosa quantified the fog on the hills adjacent to the city, one of his three-dimensional prototypes, a prismatic catcher named Macrodiamante [13], (see Fig. 2).

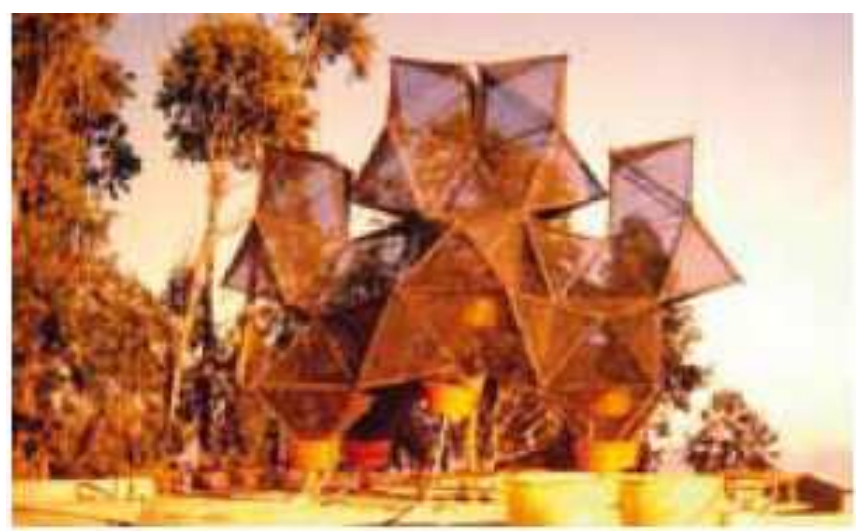

Fig. 2 Fog collector Macrodiamante.

Since 2014, Dr. David Vinicio Carrera Villacrés has been working with fog collectors systems in the rural communities in the Andes region in Ecuador [14] (see Fig. 3 ). The Warka Water is a tower of the circular structure of approximately $8 \mathrm{~m}$ high. It is built with a combination of low-cost materials that are easy to obtain. The guide for the construction and the dimensions are on the official Warka Water Desing portal [15]. The creator is Arturo Vittori (see Fig. 4).

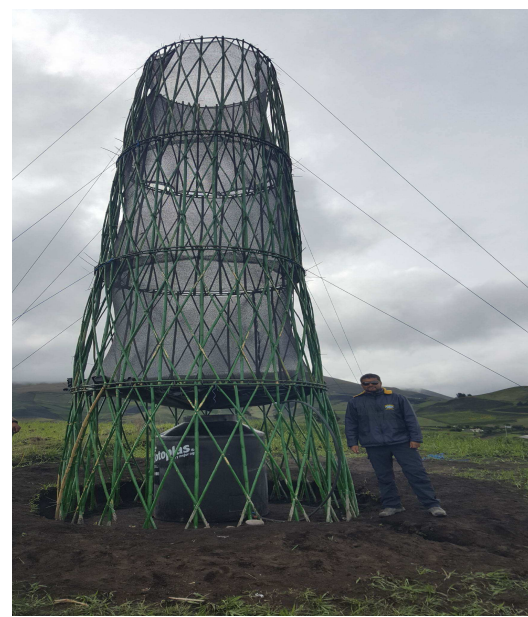

Fig. 3 Urku Yaku. 


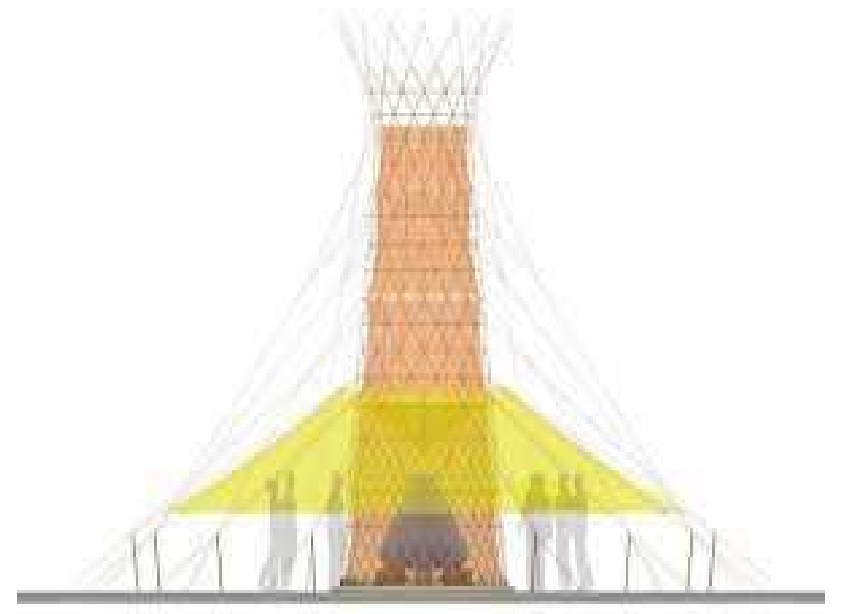

Fig. 4 Warka Water.

\section{Internet of Things Technology for Remote Environmental Monitoring}

The IoT is a network of objects or things. In this network, objects of everyday life are embedded with microcontrollers, sensors, and software that enables objects to collect and communicate data. IoT technology involves online monitoring and efficient collection and dissemination of data and information. Moreover, The IoT technology enables low power devices to transmit over long range distances [8]. Thus, IoT paradigm suits particularly well to environmental monitoring (see Fig. 5). Figure 5 summarizes a typical IoT network. By using LoRa radio frequency, monitoring devices send information to a gateway. The gateway enables IP communication via $\mathrm{WiFi}$, satellite, cable Ethernet connections, etc. Thus, information is fueled from nearby or remote monitoring locations.

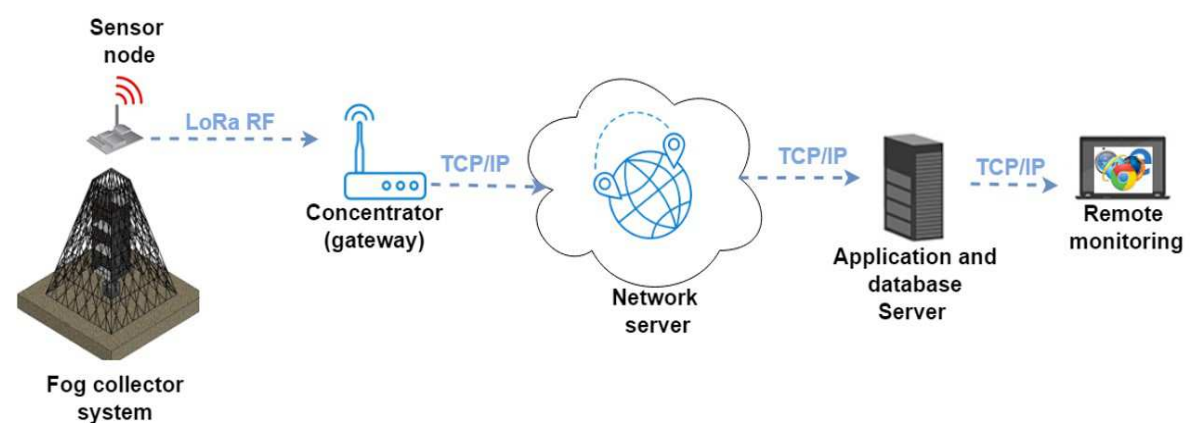

Fig. 5 LoRa WAN Architecture

\section{MATERIALS AND METHOD}

\section{A. Location and Construction of Fog Collector System}

We deployed the proposed fog collector system at the Ilalo region. This region has the highest rate of soil and water degradation in Ecuador. The construction of the condensation tower was completed on July 23, 2019.
Whereas, the sensors nodes were deployed on August 10, 2019. In the Ilalo region, the average annual rainfall is 841 $\mathrm{mm}$ and the average monthly evapotranspiration rate is 60.4 $\mathrm{mm}$. In this region, the rate of rainfall lost water through the soil surface is $86 \%$ [16]. Figure 6 shows the location where the proposed fog collector system is deployed.

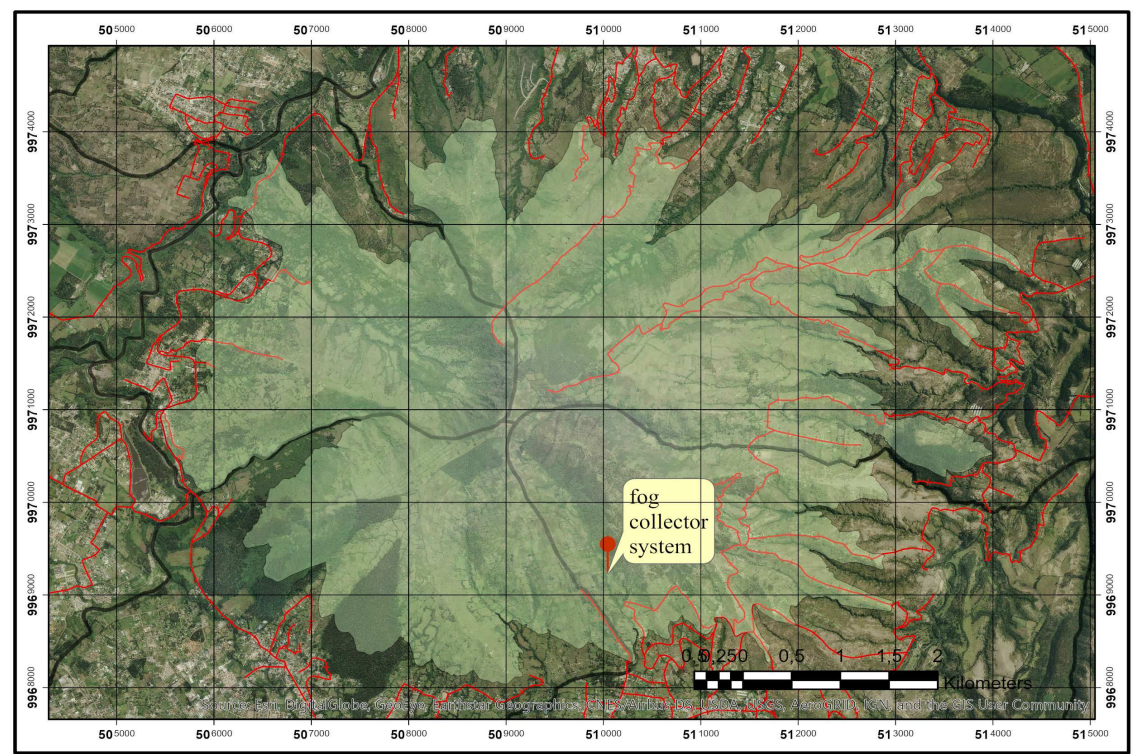

Fig. 6 Location fog collector system
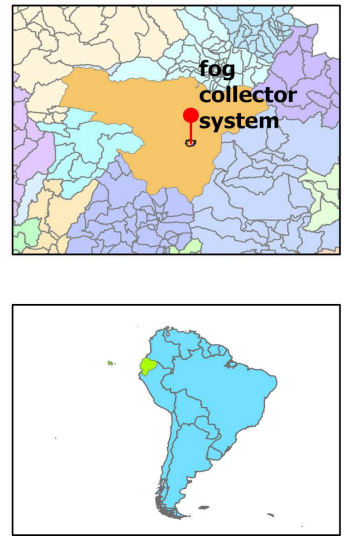

fog collector system Ilalo Volcano + road network $\square$ Parish Boundary Quito DM orthomosaic RGB

Red: Band_1
Green: Band_2

Blue: Band_3 


\section{B. LoRa Sensor Network Deployment and Monitoring System}

Theoretically LoRa devices can transmit over a range of several kilometers $(\mathrm{km})$ in Line of Sight Conditions (LOS). However, to determine the maximum transmission range in a real scenario, it is needed to perform several transmission tests in the deployment area. Thus, the transmission distance was determined by testing the conditions of the deployment area in The Andes. An optimal distance of $400 \mathrm{~m}$ was defined.

The deployment and building processes of circular and conical condensation towers are well documented in previous work. In this work, we have deployed a square condensation tower design. This square design will allow us to compare water condensation performance between these tower designs in future works. The square condensation tower consists of a sectioned catcher of $1.5 \mathrm{~m}$ per side and 6 $\mathrm{m}$ high. Figure 7 shows a picture of the deployed condensation tower design.

Figure 7 shows the architecture of the deployed monitoring system. A sensor node with LoRa transceiver was placed along with the fog collector tower. Data transmitted by the sensor node is received by a LoRa Gateway. Afterward, data is sent to an application and database server through IP networks. The application server implements a web-based interface to allow online access to the monitoring information. Figure 8 shows the web-based monitoring interface [17].

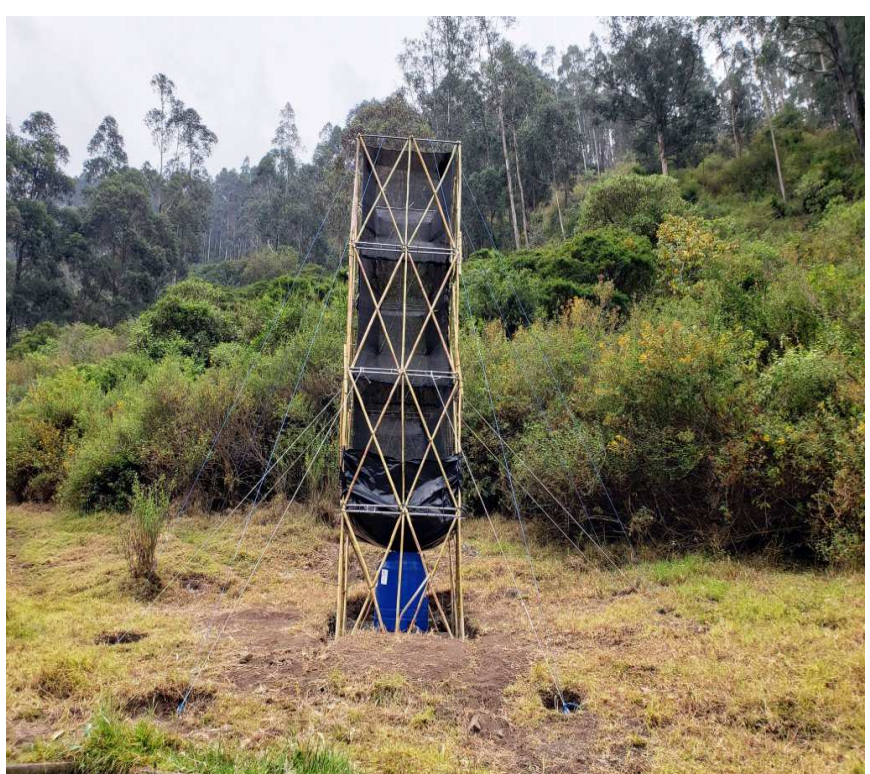

Fig. 7 Condensation tower design

\section{Data Storage and Information Processing}

The sensor node sends the sensing data every 4 hours. Data is stored in an application and database server located at the University of Bern in Switzerland. The statistical software" R Studio" was used to analyze the relationship between temperature, humidity, amount of light, tank liquid level, air pressure, cloudiness, and wind speed. Variable correlation, linear regression, and dispersion models.

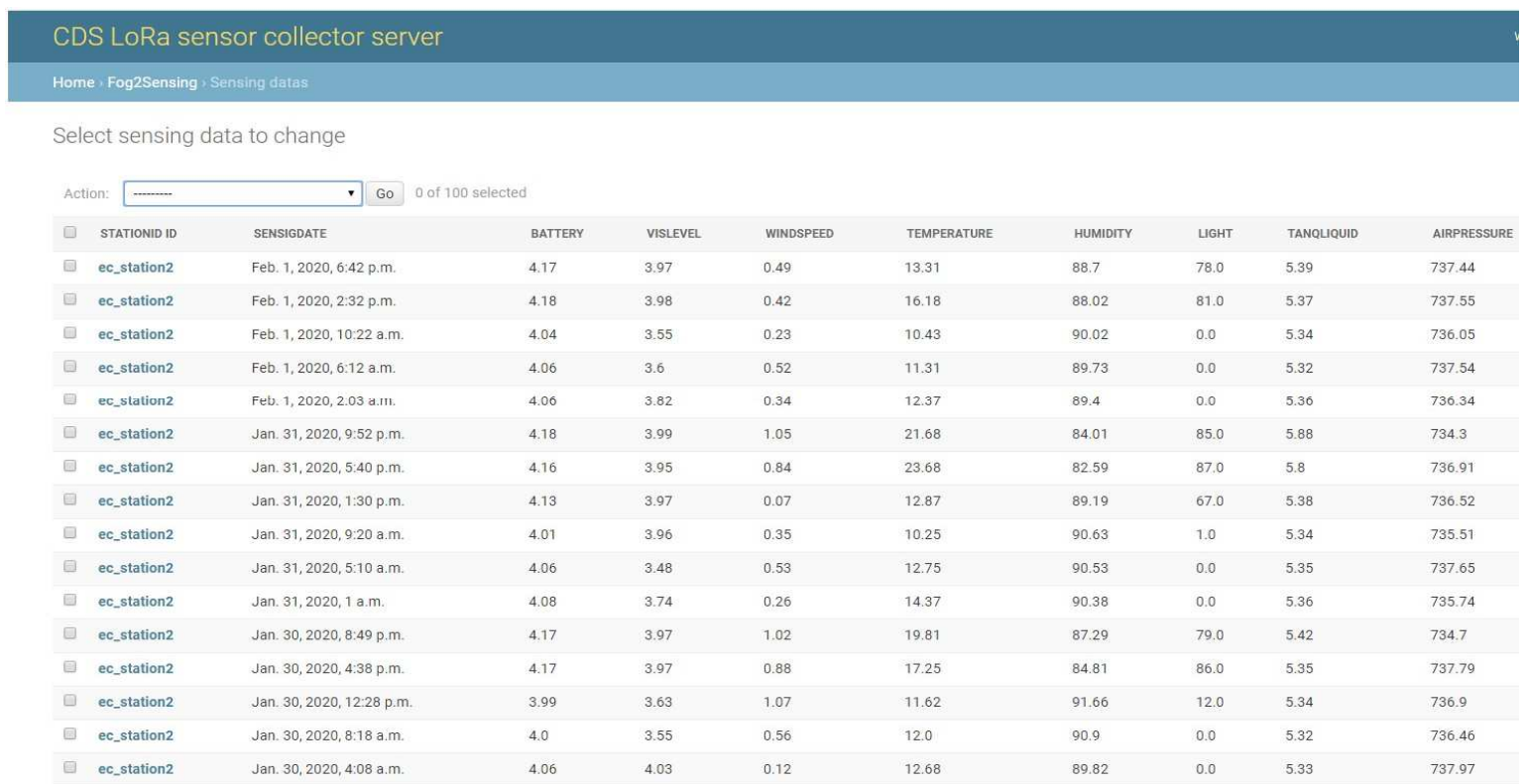

Fig. 8 Web monitoring interface

This was applied to determine the relationship between the environmental variables. Thus, the correlation coefficient, standard error, and R squared metrics were evaluated.

\section{RESULTS AND DISCUSSION}

\section{A. Fog Collector System}

In the Andean region of Ecuador, it has been proved that it is feasible to provide alternative water sources by using fog collector systems. After one year of monitoring, we have shown that fog collector systems are able to capture up to 20 liters per square meter of mesh [18]. We have tested several condensation towers designs, such as rectangular screens, cylindrical, and polyhedral shapes. The effective condensation area in the tower is usually only a few square meters $\left(0.510 \mathrm{~m}^{2}\right)$ and the water harvest rate varies from 0.2 to $4 \mathrm{~L} / \mathrm{m}^{2}$-day [19].

Manual data collection is rather complicated in the Andes region due to difficult access conditions. Thus, this work aims to provide an IoT solution to automatically monitor and 
collect environmental information along the water condensation process. Figure 9 shows the installation of the IoT sensor devices in the condensation tower.

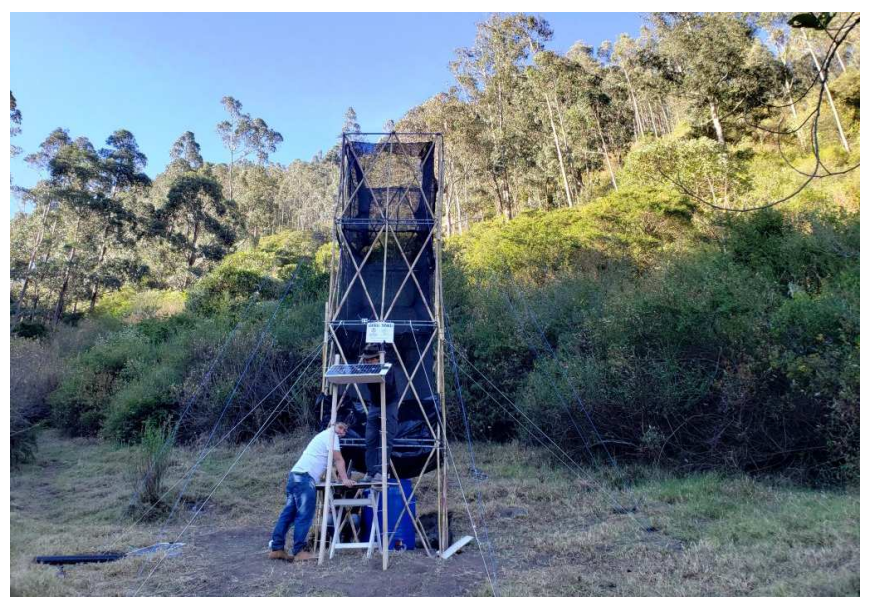

Fig. 9 Installation of sensors fog collector system

\section{B. Relationship Among the Environmental Variables and the Water Harvesting Process}

To establish a relationship between the environmental variables, the tank liquid level sensor data was defined as independent variable. Whereas, the meteorological sensor data were defined as dependent variables. Table 1 summarizes the computed correlation of the environmental variables along the water condensing process.

TABLE I

CORRELATION VALUES

\begin{tabular}{|l|c|c|c|c|}
\hline $\begin{array}{l}\text { Meteorological } \\
\text { variables }\end{array}$ & Estimated & $\begin{array}{c}\text { Error } \\
\text { Standard }\end{array}$ & T value & $\begin{array}{c}\text { Pr } \\
\text { major t }\end{array}$ \\
\hline Solar powered & 0 & 0.10 & 0 & 1.0 \\
Temperature & 0.13 & 0.21 & 0.64 & 0.52 \\
Humidity & -0.15 & 0.13 & -1.21 & 0.23 \\
Optical Fog Sensor & -0.06 & 0.21 & -0.28 & 0.78 \\
Air Pressure & -0.10 & 0.12 & -0.83 & 0.41 \\
Liquid level sensor & -0.02 & 0.13 & -0.12 & 0.90 \\
Anemometer & -0.17 & 0.12 & -1.41 & 0.16 \\
\hline
\end{tabular}

Results show that there is not a high percentage of the relationship between the liquid level sensor data and the meteorological sensor information. To verify this information, Pearson's correlation between meteorological variables and the liquid level sensor data was realized. Table 2 summarizes Pearson's correlation values.

TABLE II

PEARSON'S CORRELATION

\begin{tabular}{|c|c|c|c|c|c|c|c|}
\hline Meteo & Tem & Humi. & Solar & $\begin{array}{l}\text { Liq. } \\
\text { level }\end{array}$ & \begin{tabular}{|l} 
Pressur \\
$\mathrm{e}$
\end{tabular} & $\begin{array}{l}\text { Optical } \\
\text { Fog } \\
\end{array}$ & Anemo. \\
\hline Temp. & 1.0 & -0.31 & 0 & 0.85 & 0.060 & -0.21 & 0.61 \\
\hline Humi. & -0.31 & 1.0 & -0.38 & -0.09 & -0.41 & -0.22 & -0.24 \\
\hline Solar P. & 0.85 & -0.38 & 1.0 & 0.024 & -0.08 & 0.62 & 0.52 \\
\hline $\begin{array}{l}\text { Liquid } \\
\text { level }\end{array}$ & 0.06 & -0.09 & 0.24 & 1.0 & -0.07 & 0.02 & -0.11 \\
\hline $\begin{array}{l}\text { Air } \\
\text { Pressure }\end{array}$ & -0.21 & -0.41 & -0.08 & -0.07 & 1.0 & -0.07 & 0.074 \\
\hline $\begin{array}{l}\text { Optical } \\
\text { Fog }\end{array}$ & 0.61 & -0.22 & 0.62 & 0.02 & 0.072 & 1.0 & 0.295 \\
\hline $\begin{array}{l}\text { Anemome } \\
\text { ter }\end{array}$ & 0.48 & -0.24 & 0.52 & -0.11 & 0.074 & -0.29 & 1.0 \\
\hline
\end{tabular}

Pearson's correlation results show that most of variables are not highly correlated, that is, correlation value lower than 0.7. However, temperature and solar power data show a correlation value of 0.854 . A directly proportional relationship can also be observed between the Optical Fog Sensor and temperature which correlation value is 0.612 . The average monthly precipitation of the data processing of the last 27 years in Quito shows the seasonality of the city (Figure 10).

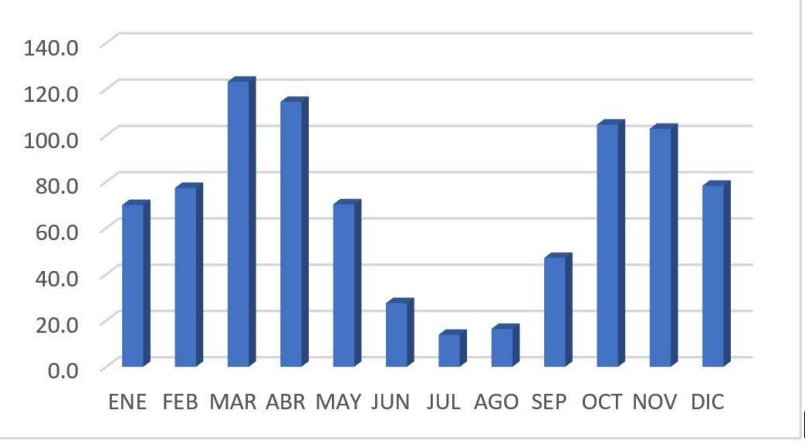

Fig. 10 Average monthly rainfall

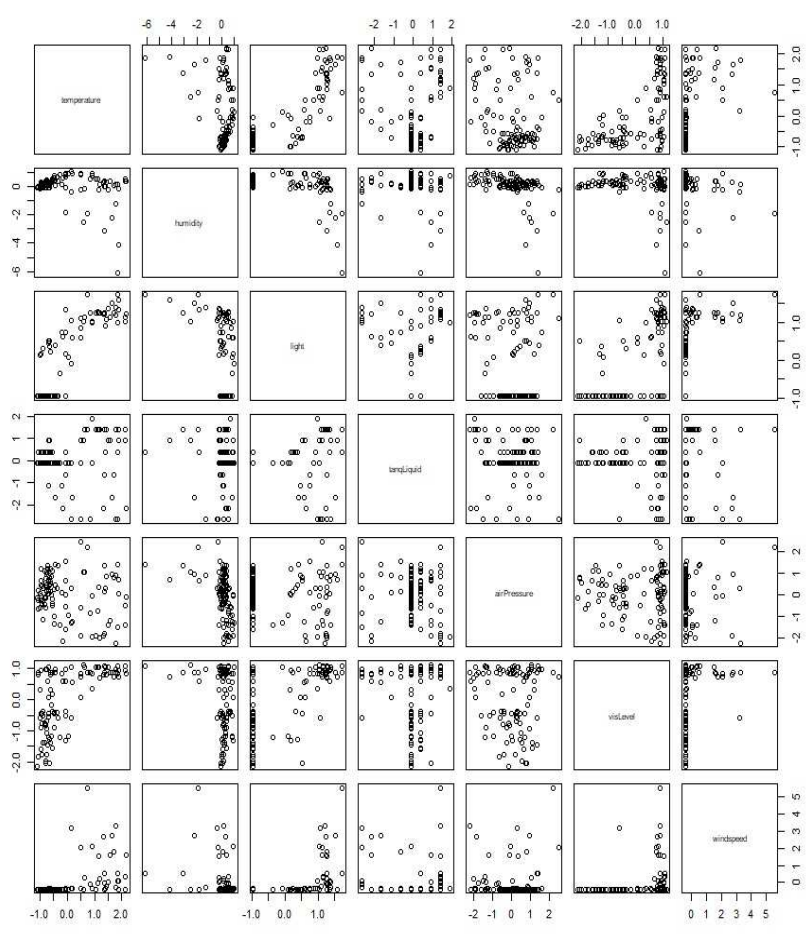

Fig. 11 Correlations

It can be explained that there is a deficiency of precipitation for the months of June, July and August being the drought season. The correlation results are affected by the temporality, and the small amount of data in the different seasons of the year being necessary a study with greater amount of data (Figure 12). The relationship between the different meteorological variables is low. This is due to the small amount of collected information. Authors of [20] mention that small samples have a remove a low power and these only improve when the sample is large $\mathrm{T}=500$, where $\mathrm{T}=$ number of samples. 


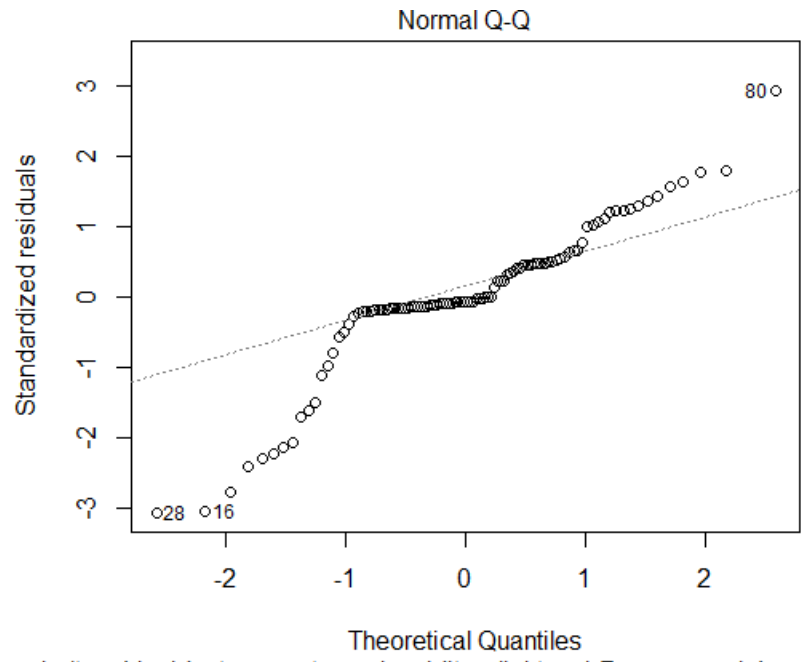

Im(tanqLiquid $\sim$ temperature + humidity + light + airPressure + visLevel + w Fig. 12. Normal QQ plot for Standardized Error

The fog collector systems in operation can see in the Figure 13 .

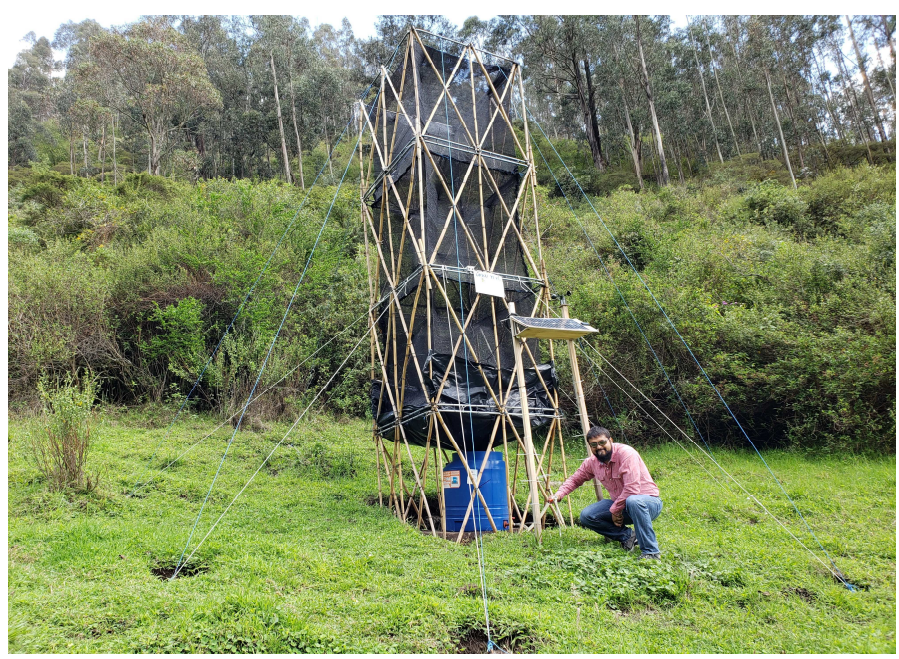

Fig. 13. Fog collector sistema in operation

\section{CONCLUSION}

In this work, we have implemented a fog harvesting and IoT based environment monitoring system to monitor environmental parameters while providing alternative water sources. We have deployed our system in the Ilalo volcano area. Our system enables the monitoring of meteorological parameters by using IoT technology. Furthermore, we have performed a data analysis process to determine the correlation between environmental variables and the water harvesting process. However, the short operating time has prevented any type of statistical correlation from being found. Nevertheless, data analysis shows a high correlation between temperature, solar power, and optical fog sensor data. We demonstrated the feasibility of providing alternative water sources by using fog collector systems.
Moreover, we provided a technological framework to enable real time monitoring and data interpretation at the Ilalo volcano in the Andes region of Ecuador.

\section{REFERENCES}

[1] B. Roca Villanueva, M. Beltrán Salvador, and R. Gómez Huelgas, "Change climate and health," Rev. Clin. Esp., vol. 219, no. 5, pp. 260-265, 2019.

[2] D. Cruzat and C. Jerez-Hanckes, "Electrostatic fog water collection," J. Electrostat., vol. 96, no. October, pp. 128-133, 2018.

[3] S. Montecinos, D. Carvajal, P. Cereceda, and M. Concha, "Collection efficiency of fog events," Atmos. Res., vol. 209, pp. 163-169, 2018.

[4] Y. Lyu and P. Yin, "Internet of Things transmission and network reliability in complex environment," Comput. Commun., vol. 150, pp. 757-763, 2020.

[5] G. Carrillo-Rojas et al., "Atmosphere-surface fluxes modeling for the high Andes: The case of páramo catchments of Ecuador," Sci. Total Environ., vol. 704, p. 135372, 2020.

[6] C. Coltorti, M., Ollier, "Geomorphic and Tectonic evolution of the Ecuadorian Andes," Geomorphology, vol. 32, no. 1-2, pp. 1-19, 2000.

[7] B. Hansjürgens, A. Lienkamp, and S. Möckel, "Justifying Soil Protection and Sustainable Soil Management: Creation-Ethical, Legal and Economic Considerations," Sustainability, vol. 10, no. 10, p. 3807,2018

[8] S. K., "A review analysis on the role of soils in watershed management," J. Geotech. Enginnering, vol. 5, no. 1, pp. 23-29, 2018.

[9] C. M. Regalado and A. Ritter, "On the estimation of potential fog water collection from meteorological variables," Agric. For. Meteorol., vol. 276-277, no. December 2018, p. 107645, 2019.

[10] D. M. Fernandez et al., "Fog water collection effectiveness: Mesh intercomparisons," Aerosol Air Qual. Res., vol. 18, no. 1, pp. 270283, 2018.

[11] C. M. Regalado and A. Ritter, "The design of an optimal fog water collector: A theoretical analysis," Atmos. Res., vol. 178-179, pp. 4554, 2016.

[12] M. Fessehaye, S. A. Abdul-Wahab, M. J. Savage, T. Kohler, T. Gherezghiher, and H. Hurni, "Fog-water collection for community use,” Renew. Sustain. Energy Rev., vol. 29, pp. 52-62, 2014.

[13] P. Cereceda, J. Leiva, J. de D. Rivera, and P. Hernández, Agua de Niebla. Coquimbo, 2014.

[14] A. Lulla, "Cloud-catching to bubble science," New Sci., vol. 235, no 3143, pp. 18-19, 2017.

[15] A. Vittori, "Warka Water. La torre de bambú que produce hasta 100 litros de agua al día," http://www.warkawater.org/, 2019. [Online]. Available: http://www.warkawater.org/. [Accessed: 31-Dec-2019].

[16] Instituto Nacional de Metereología y Climatología INAMHI, "Boletines Climáticos y Agrícolas," 2017. [Online]. Available: http://www.serviciometeorologico.gob.ec/.

[17] J. Xu et al., "Data Transmission Method for Sensor Devices in Internet of Things based on Multivariate Analysis," Measurement, p. 107536, 2020.

[18] D. V. Carrera-Villacrés, I. C. Robalino, F. F. Rodríguez, W. R. Sandoval, D. L. Hidalgo, and T. Toulkeridis, "An innovative fog catcher system applied in the Andean communities of Ecuador," Trans. ASABE, vol. 60, no. 6, pp. 1917-1923, 2017.

[19] C. M. Regalado and A. Ritter, "The performance of three fog gauges under field conditions and its relationship with meteorological variables in an exposed site in Tenerife (Canary Islands)," Agric. For. Meteorol., vol. 233, pp. 80-91, 2017.

[20] J. C. Alonso and S. Montenegro, "Estudio de Monte Carlo para comparar 8 pruebas de normalidad sobre residuos de mínimos cuadrados ordinarios en presencia de procesos autorregresivos de primer orden," Estud. Gerenciales, 2015. 